\title{
La contribución para la educación y promoción cooperativa y otros fines de interés público - COFIP_ en la ley vasca y su aplicabilidad ${ }^{1}$
} (The contribution for education and promotion of cooperatives and other public interest purposes - COFIP - in the basque law and its applicability)

\author{
Gotzon Gondra Elgezabal² \\ Universidad de Deusto (España)
}

Sumario: 1. Introducción. 2. Breve aproximación al fondo y su actual regulación en la legislación vasca. 3. Régimen de la contribución para la educación y promoción cooperativa y otros fines de interés público. 4. Aplicaciones de la COFIP. 5. Eventual régimen especial de aplicabilidad del fondo derivado de la normativa COVID-19. 6. Consecuencias de la inobservancia del régimen de la COFIP. 7. Bibliografía.

Summary: 1. Introduction. 2. Brief introduction to the fund and its current legal regulations in the Basque legislation. 3. Legal regulations of the Contribution for Education and Promotion of Cooperatives and other Public Interest Purposes. 4. Application of the COFIP. 5. Temporary special regulations of the applicability of the fund derived from the COVID-19 regulation. 6. Consequences of the noncompliance with the COFIP regulations. 7. Bibliography.

Resumen: Una de las principales particularidades del régimen económico de las sociedades cooperativas es, sin duda, la existencia de un fondo obligatorio cuya aplicabilidad viene expresamente regulada, no siendo los importes dotacionales que la conforman disponibles por los administradores. Se trata de

1 Este trabajo forma parte del Proyecto de Investigación titulado «Las cooperativas como instrumento de política de empleo ante los nuevos retos del mundo del trabajo» (RTI2018-097715-B-I00). El proyecto ha sido financiado por el Ministerio de Ciencia, Innovación y Universidad del Gobierno español, la Agencia Estatal de Investigación y el Fondo Europeo de Desarrollo Regional de la Unión Europea, en el marco de la Convocatoria correspondiente a 2018 de Proyectos de I+D+i «Retos de investigación» del Programa Estatal de I+D+i orientado a los retos de la sociedad

2 Abogado. Profesor de Derecho Mercantil de la Facultad de Derecho de la Universidad de Deusto. Email: gotzon.gondra@deusto.es 
la denominada por el legislador vasco como Contribución para la educación y promoción cooperativa y otros fines de interés público. Si bien las especialidades de la naturaleza jurídica y las finalidades perseguidas por dicho Fondo vienen siendo, ya de antiguo, materias de interés para su investigación, se estima que tanto la aprobación de la nueva legislación cooperativa autonómica como la explícita referencia al fondo contenida en la legislación aprobada al objeto de la ordenación de la situación excepcional de alarma por la COVID-19 invitan a profundizar en el estudio de su evolución jurídica y práctica (eventuales y potenciales destinos).

Palabras clave: COFIP, Fondo Obligatorio, Educación y Promoción, Interés Público, COVID-19.

Abstract: One of the main peculiarities of the financial regulations of cooperative societies is, undoubtedly, the existence of a mandatory fund whose applicability is expressly regulated and whose endowment is not accessible to the administrators. Basque legislation refers to it as the Contribution for Education and Promotion of Cooperatives and other Public Interest Purposes. Although the characteristics of the legal nature and the purpose of the said Fund have long been the focus of research, it is considered that both, the approval of the new cooperative legislation of the Basque autonomous region and the explicit reference to the fund contained in the approved legislation for the purpose of managing the exceptional situation of emergency generated by the COVID-19, lead to a deeper study of its legal and practical evolution (possible and potential future purposes).

Keywords: COFIP, Mandatory Fund, Education and Promotion, Public Interest, COVID-19. 


\section{Introducción}

Característica inherente a la Cooperativa ha sido siempre el desarrollar su actividad en una doble faceta, que la diferencia sustancialmente del actuar del resto de sociedades clásicas que operan en el mercado.

Por un lado ha de operar en el mercado ajustándose necesariamente a las técnicas propias que configuran la actuación empresarial. Sin embargo, en su otra vertiente, la Cooperativa debe encaminarse al logro de fines diversos de los estrictamente empresariales, como son la función educativa de sus socios y la promoción de los intereses económicos y sociales, tanto de sus miembros, como del entorno donde va a desenvolverse.

Es por ello por lo que en la configuración jurídica de la sociedad cooperativa aparecen figuras absolutamente novedosas en el Derecho general de sociedades, como es el caso de la «Contribución para la educación y promoción cooperativa y otros fines de interés público» — en adelante COFIP_- en la legislación vasca ${ }^{3} y$ cuya existencia debe ponerse en relación fundamentalmente con el $V$ Principio Cooperativo -Educación, formación e información- de la Declaración de la Alianza Cooperativa Internacional (en adelante $\mathrm{ACl}$ ), según su formulación en el Congreso de Manchester (Septiembre de 1995), en consonancia con el VI — Cooperación entre Cooperativas - y VII — Interés por la Comunidad-, que son pautas mediante las cuales las cooperativas ponen en práctica sus valores.

No obstante, cabe subrayar que, si bien la $\mathrm{ACl}$, dentro de sus recomendaciones, sugiere a los distintos ordenamientos que establezcan con libertad los parámetros de distribución de excedentes entre los fondos irrepartibles (Fondo de Reserva Obligatorio y COFIP, o Fondo de Educación y Promoción Cooperativa —en adelante FEPC - , como viene a denominarse más habitualmente en otras legislaciones ${ }^{4}$, ordenamientos como el de la Comunidad Autónoma del País Vasco y el resto del Estado, optan por la obligatoriedad de dotar dicho fondo, sin subordinar su constitución a una expresa previsión estatutaria o a la existencia de acuerdo asambleario en tal sentido. De ahí que el mencionado Fondo goce de cierta tradición en España, en cuanto viene siendo contemplada por sus antecedentes legislativos.

3 Equivalente al más comúnmente denominado como Fondo de Educación y Promoción Cooperativa.

${ }^{4}$ Ver Gadea, E., Sacristán, F. y Vargas Vasserot, C.: «Régimen jurídico de la Sociedad cooperativa del Siglo XXI. Realidad actual y propuestas de reforma». Editado por Dykinson, S.L. Madrid 2009, pp. 501-505 
Nos hallamos por tanto ante una figura jurídica extendida y ampliamente reconocida y a la que las Leyes prestan especial atención para configurar la estructura de la sociedad cooperativa en consonancia con sus fines distintivos y para regular el desarrollo de la totalidad de su vida social, tanto en su vertiente interna como en la externa de interrelación con la comunidad e incluso con los poderes públicos, especialmente en las facetas contributivas y de control administrativo.

Es por ello que por la presente se pretende llevar a cabo un estudio del recorrido seguido por un elemento tan determinante para la singularidad societaria y cooperativa, como es su COFIP (FEPC), a través de la realidad y su evolución jurídica en el marco de la legislación autonómica vasca. Todo ello procurando por un lado rescatarlo del olvido al que se estima ha venido siendo sometido a lo largo de los años, aprovechando su expreso reconocimiento como medida extraordinaria de ajuste económica en el marco de la normativa aprobada con motivo de la COVID-19 (Real Decreto-ley 15/2020, de 21 de abril, de medidas urgentes complementarias para apoyar la economía y el empleo; BOE 22 de abril de 2020), y por otro trazar posibles «nuevas» líneas de actuación —destinos - que contribuyan a su óptima aplicación, compaginando la gestión socio-cultural (objetivos sociales y culturales) con los comunicativos de la propia Cooperativa.

\section{Breve aproximación al fondo y su actual regulación en la legislación vasca}

Fue la Alianza Cooperativa Internacional la que, en su reunión celebrada en Manchester en 1995, procedió a aprobar lo que se denomina la Declaración de Identidad Cooperativa, en cuyo marco se determinaron el concepto universal, los valores y los principios cooperativos (7).

Entre los mencionados principios se encontraban los siguientes:

5. Educación, formación e información.

6. Cooperación entre cooperativas.

7. Compromiso con la Comunidad.

De esta manera, y al objeto de promover, fomentar y facilitar el desarrollo de los principios señalados, el legislador procuró la obligatoriedad de la dotación de un fondo que, sin poner en riesgo la viabilidad del proyecto cooperativo (obligatoriedad vinculada a la obtención de resultados positivos por la Sociedad o la interposición de sanciones a los socios), tuviera como objetivo — finalidad - el desarrollo de actuaciones que pudieran enmarcarse en aquellos principios. 
Todo ello siguiendo la línea previamente establecida por la propia $\mathrm{ACl}$ según formulación acordada en el Congreso de Viena (1966), por la que todas las cooperativas debían constituir un fondo destinado a impartir la enseñanza de los principios y métodos de la cooperación, en el plano económico y democrático, a sus miembros, dirigentes, empleados y al público en general.

Fondo cuya regulación en el ámbito autonómico vasco ha tenido la siguiente evolución ${ }^{5}$ :

\section{a) Ley 1/1982, de 11 de febrero, de Cooperativas ${ }^{6}$}

En virtud de cuanto disponen los artículos 148 y 149 de la Constitución española de 27 de diciembre de 19787, la Comunidad Autónoma del País Vasco ha desarrollado su competencia exclusiva en materia cooperativa mediante la oportuna aprobación de su propia legislación sobre el referido tipo jurídico, toda vez que el mismo queda al margen de la legislación mercantil.

En base a lo señalado, la Comunidad Autónoma del País Vasco se arrogó dicha competencia a través del artículo 10.23 de la Ley Orgánica 3/1979, de 18 de diciembre, de Estatuto de Autonomía para el País VasCo ${ }^{8}$, que dispone que la Comunidad Autónoma del País Vasco tiene competencia exclusiva en las siguientes materias:

23. Cooperativas, Mutualidades no integradas en la Seguridad Social y Pósitos, conforme a la legislación general en materia mercantil.

Competencia exclusiva que se materializó en la primera legislación cooperativa del estado, anterior incluso a la propia ley estatal (Ley 27/1999, de 16 de julio, de Cooperativas), mediante la aprobación de la Ley 1/1982, de 11 de febrero, de Cooperativas, que en su art. 27 regulaba expresamente el Fondo de Educación y Promoción Social como un fondo obligatorio.

Fondo que se regulaba como inembargable, al que había que destinar anualmente al menos un $10 \%$ de los excedentes netos deduci-

5 Ver Nagore, I.: «Regulación en la legislación cooperativa vasca de la contribución para la educación y promoción cooperativa y otros fines de interés público y cuestiones que plantea». Boletín de la Asociación Internacional de Derecho Cooperativo, n. ${ }^{\circ} 57$. Bilbao 2020. Pp. 253-278.

6 BOPV núm. 33 de 10 de marzo de 1982 y BOE núm. 100 de 26 de abril de 2012.

7 BOE núm. 311 de 29 de diciembre de 1978.

8 BOE núm. 306, de 22 de diciembre de 1979. 
dos los impuestos, una vez el Fondo de Reserva Obligatorio alcanzase un importe igual al $50 \%$ del Capital Social (pudiendo ser la dotación del $5 \%$ en el supuesto de que el Fondo de Reserva Obligatorio no alcanzase el referido 50\% del Capital Social), así como el importe de las multas y demás sanciones que por vía disciplinaria se pudieran imponer por la Cooperativa a sus socios. Todo ello, siendo la finalidad de dichas cantidades dotacionales:

a. El fomento de la asistencia técnica, la creación de supraestructuras de apoyo a las Cooperativas y, en general, cuantas actividades puedan enmarcarse en el principio de la intercooperación.

b. La formación y educación de los socios en los principios y técnicas cooperativas, así como la difusión de las características de cooperativismo en el medio social en que se desenvuelva la actividad de la Cooperativa.

c. De carácter cultural, profesional o benéfico, con destino a la promoción Social del entorno local o de la comunidad en general.

b) La Ley 4/1993, de 24 de junio, de Cooperativas de Euskadi ${ }^{9}$

La mencionada regulación quedó derogada con la aprobación de la Ley 4/1993, de 24 de junio, de Cooperativas de Euskadi, que disponía en su art. 68 como Fondo Obligatorio el de Educación y Promoción Cooperativa, cambiando así su denominación original (Fondo de Educación y Promoción Social), manteniéndose su carácter inembargable, destinándose al mismo al menos el 10\% de los excedentes disponibles y el importe de las sanciones económicas que imponga la cooperativa a sus socios ${ }^{10}$.

Y ello para su aplicación a alguna o varias de las siguientes finalidades:

a) La formación y educación de sus socios y trabajadores en los principios cooperativos y en sus valores o en materias relacionadas con el trabajo y demás actividades cooperativas.

b) La promoción de las relaciones intercooperativas, incluyendo la cobertura de gastos por la participación en cooperativas de segundo grado, cooperativas de integración y demás entidades

9 BOPV núm. 135 de 19 de Julio de 1993 y BOE núm. 35 de 10 de febrero de 2012.

10 Ver Alzola, I. y Esnaola, J.M.: «Régimen económico: los fondos sociales obligatorios», Manual de derecho de Sociedades Cooperativas, editado por el Consejo Superior de Cooperativas de Euskadi. Vitoria-Gasteiz 2007, pp. 183-190. 
creadas para la promoción, asistencia, dirección común o actividades de apoyo entre cooperativas.

c) La promoción cultural, profesional y asistencial, así como la difusión de las características del cooperativismo en el entorno social en que se desenvuelva la cooperativa y en la sociedad en general.

Es decir, viene a desarrollar las finalidades ya dispuestas por la legislación anterior ${ }^{11}$, incorporando aspectos como su reflejo contable (deberán figurar en el pasivo del balance con separación de otras partidas) y regulando límite temporal para llevar a cabo la misma, estableciendo una alternativa para el supuesto de su incumplimiento (el importe del referido fondo que no se haya aplicado deberá materializarse, dentro del ejercicio económico siguiente a aquel en que se haya efectuado la dotación, en títulos de la Deuda Pública de la Comunidad Autónoma del País Vasco, cuyos rendimientos financieros se aplicarán al mismo fin. Dichos títulos no podrán ser pignorados ni afectados a préstamos o cuentas de crédito).

Regulación que, como veremos más adelante, toma claramente como referencia el legislador estatal en la Ley $27 / 1999$.

c) Ley 6/2008, de 25 de junio, de la Sociedad Cooperativa Pequeña de Euskadi $^{12}$

Con efectos desde el día 1 de enero de 2009, la Ley 6/2008, de 25 de junio, de la Sociedad Cooperativa Pequeña de Euskadi, dispuso, en base a la regulación contenida en su Disposición Adicional Cuarta, una modificación del art. 68 de la Ley 4/1993, sustituyendo el término Fondo de Educación y Promoción Cooperativa por Contribución para Educación y Promoción Cooperativa y Otros Fines de Interés Público (comúnmente abreviado como COFIP); denominación tomada como base en el desarrollo del presente estudio.

Sin entrar a valorar el procedimiento técnico jurídico seguido para la modificación de la regulación del fondo, consideraba por quien suscribe cuando menos sorprendente, a través de una disposición adicional incorporada a una ley que tenía por objeto la regulación específica de un tipo de cooperativa concreto (Pequeña), cabe destacar, además

11 Ver Gadea, E.: «Derecho de las cooperativas. Análisis de la Ley 4/1993, de 24 de junio, de cooperativas del País Vasco», editado por la Universidad de Deusto. 1999, pp. 222-225. 2011.

12 BOPV núm. 127 de 04 de Julio de 2008 y BOE núm. 212 de 03 de septiembre de 
del cambio de denominación ya señalada, los cambios de aplicabilidad derivada también de aquélla:

a) La formación y educación de sus socios y trabajadores sobre el cooperativismo, actividades cooperativas y otras materias no relacionadas con el puesto de trabajo.

b) La promoción de las relaciones intercooperativas, incluyendo la cobertura de gastos por la participación en entidades creadas para la promoción, asistencia, dirección común o actividades de apoyo entre cooperativas.

c) La promoción educativa, cultural, profesional y asistencial, así como la difusión de las características del cooperativismo, en el entorno social en que se desenvuelva la cooperativa y en la sociedad en general, y la promoción del uso del euskera.

d) La promoción de nuevas empresas cooperativas mediante aportaciones dinerarias a una entidad sin ánimo de lucro promovida por el movimiento cooperativo vasco.

Añadiéndose en esta nueva regulación que la canalización para la consecución de las finalidades a), b) y c) podrá llevarse a cabo de manera también indirecta, a través de entidades sin ánimo de lucro o de entidades de intercooperación, mediante la puesta a disposición parcial o íntegra de las cantidades dotacionales del fondo a favor de aquéllas. Siempre condicionado a que el destino final de las mencionadas cantidades se ajuste a alguna de las finalidades legalmente dispuestas.

Y ello, al mismo tiempo que viene a modificar el destino de las citadas cantidades para el supuesto de su no aplicación dentro del plazo legalmente establecido, pasando de tener que materializarse en títulos de la Deuda Pública de la Comunidad Autónoma del País Vasco, a tener que entregarlo a entidades sin ánimo de lucro para su destino a las finalidades de interés público establecidas para esta contribución.

Todo ello reiterando tanto el carácter inembargable del fondo, como las cantidades que deben destinarse al mismo y su debido reflejo en el pasivo del balance.

d) Ley 11/2019, de 20 de diciembre, de Cooperativas de Euskadi13

Para finalizar, la señalada denominación (Contribución para Educación y Promoción Cooperativa y Otros Fines de Interés Público) se ha mantenido en el marco de la Ley 11/2019, de 20 de diciembre,

13 BOPV núm. 135 de 19 de Julio de 1993 y BOE núm. 35 de 10 de febrero de 2012. 
de Cooperativas de Euskadi, haciendo suya de esta manera la modificación contenida en la Ley 6/2008.

Ley que ha venido a mantener también el resto de características previamente reguladas por la Ley 6/2008 para el fondo en los términos ya expuestos, procurando únicamente añadir una nueva potencial finalidad (art. 72.1), como esla formación y educación de las personas socias y trabajadoras para el fomento en las sociedades cooperativas de una política efectiva para avanzar hacia la igualdad de mujeres y hombres. Y ello, toda vez que la promoción del uso del euskera, recogida como apartado d), ya venía expresamente recogida en la anterior regulación, junto con la promoción educativa, cultural... (art. 68 Bis derivada de la Disposición Adicional Cuarta de la Ley 6/2008).

\section{Régimen de la contribución para la educación y promoción cooperativa y otros fines de interés público}

La consideración detallada de la trascendencia que, ante el Derecho, posee la COFIP requiere examinar, en un primer momento, cuál es el diseño legal que la Ley vasca de cooperativas determina, analizando sus requisitos en cuanto a su obligatoriedad, a los porcentajes de dotación, al órgano encargado de efectuarla y a los criterios y fines que han de presidir la eventual aplicación de los fondos dotados. Sólo una vez ultimado este análisis, cabrá estudiar lo que constituye el objeto principal de la presente, es decir, los criterios y fines que han de presidir la eventual aplicación de los fondos dotados.

Para finalizar llevando a cabo un breve acercamiento a las contingentes consecuencias tanto en materia societaria como de régimen fiscal, que un posible incumplimiento de tales exigencias legales haría recaer en la Cooperativa.

\section{Ingresos que conforman la COFIP}

La COFIP debe nutrirse además de con el porcentaje de los excedentes que determine la Asamblea General o preestablezcan los Estatutos Sociales, con las sanciones económicas que imponga la Cooperativa a sus socios tras la incoación del oportuno expediente disciplinario (art. 72.4 de la Ley 11/2019).

Sin perjuicio de la LCE no disponga otras fuentes de financiación para la COFIP, parece lógico concluir también como tales, tanto los rendimientos financieros que pudieran derivarse del propio fondo, 
como otros ingresos que, por su naturaleza y finalidad, resultaren imputables a la misma (subvenciones, donaciones, etc.).

En todo caso, la principal, aunque como adelantábamos no la única, fuente de ingresos de la COFIP, son los porcentajes sobre los excedentes netos que se le destinan, de conformidad con lo dispuesto por el art. 70 de la LCE, y en los Estatutos Sociales o por acuerdo de la Asamblea, en su caso [art. 33.3.c) de la LCE].

\section{Porcentajes de dotación obligatoria a la COFIP}

No existen especialidades según el tamaño o la clase de Cooperativa que deba aplicar este precepto. Atendiendo a ello, y dejando al margen la dotación obligatoria e íntegra de las cantidades derivadas de procedimientos disciplinarios con resultado de sanciones económicas, a continuación detallaremos el régimen relativo a los porcentajes de dotación a la COFIP en relación a los excedentes netos.

Así, la LCE mantiene, añadiendo una nueva finalidad, tal y como adelantábamos, la regulación contenida en la Disposición Adicional Cuarta de la LCPE, que establecía una modificación de la legislación anterior en el sentido de clarificar la naturaleza de los recursos destinados a finalidades de interés público, para lo que se revisaron tanto la denominación del Fondo, ajustándose mejor a su verdadera naturaleza, como sus finalidades, tratando de compaginar la realidad social cooperativa con el carácter de interés público de dichas finalidades, subrayando su carácter obligatorio y actualizando las características de su gestión a la nueva regulación, anualmente, de los excedentes disponibles se destinará un 20\%, como mínimo, al Fondo de Reserva Obligatorio, y un $10 \%$, como COFIP. Todo ello sin perjuicio de las dotaciones adicionales a los fines indicados que pudiera acordar la Asamblea General respecto al resto.

En todo caso, y como regla excepcional al expuesto, la legislación cooperativa vigente posibilita que en tanto en cuanto el Fondo de Reserva Obligatorio no alcance un importe igual al 50\% del Capital Social, podrán modificarse los mencionados porcentajes, destinando un $25 \%$ al Fondo de Reserva Obligatorio y un 5\% como COFIP.

Son también dos las notas características que cabe subrayar de la legislación autonómica vasca en esta materia:

- La primera viene constituida porque el porcentaje de dotación a los fondos obligatorios referenciados, que se determina en un $30 \%$, global, de los excedentes netos anuales, una vez de- 
ducidas las cantidades que se destinen a compensar pérdidas de ejercicios anteriores y atender los impuestos exigibles, tiene carácter mínimo. Dado que esos porcentajes vienen señalados imperativamente por la legislación, hay que concluir que la regla estatutaria podrá igualar o bien superar dichos porcentajes, aunque nunca reducirlos, pues lo contrario supondría introducir una cláusula sin función alguna. Es decir, no podemos obviar en este sentido el importante papel conferido a la Asamblea en esta materia cuando se establece, en relación a la aplicación de excedentes netos disponibles, una vez dotados los Fondos, su competencia para, en su caso, acordar dotaciones adicionales destinadas a los fines previstos en el marco de la COFIP.

- La segunda consiste en el carácter imperativo de la imputación de la COFIP, sin posibilidad alguna de posponer su dotación a la del Fondo de Reserva Obligatorio. ${ }^{14}$

\section{3. Órgano competente para acordar la dotación de la COFIP}

Así, resulta evidente que la imputación de esos montantes patrimoniales a la partida contable correspondiente no es automática. La distribución de excedentes debe hacerse por la Asamblea General de la Cooperativa, que ha de pronunciarse sobre la propuesta de los Administradores - Consejo Rector - en tal sentido, gozando, a diferencia de lo que ocurre en materia de Cuentas Anuales, de libertad para modificar los términos de tal propuesta, siempre que, como es obvio, respete las exigencias legales y, en su caso, estatutarias, tal y como se deriva del artículo 33.3.c) de la LCE.

\section{Reflejo contable de la COFIP}

Por otro lado, y en relación a su contabilización, dichas dotaciones se deben considerar no como distribución de resultados, sino como un gasto,

14 A diferencia de la regulación contenida por la Ley 1/1982, en la que expresamente se recogía la posibilidad de posponer la dotación al citado Fondo al que se llevara a cabo a favor del Fondo de Reserva Obligatorio; sin perjuicio de que los estatutos pudieran establecer otra cosa. La mencionada Ley se inscribía en el grupo de ordenamientos que disponían que, aun existiendo excedentes en un momento inicial, la dotación al en su día denominado Fondo de Educación y Promoción Social no era obligatorio hasta tanto en cuanto los Fondos de Reserva no alcanzasen un determinado nivel en relación al Capital Social. 
que deberá reflejarse en la Cuenta de Pérdidas y Ganancias, independientemente de que se cuantifique en función del resultado del ejercicio.

El que se trate de una partida que puede recoger características de fondo propio y de fondo ajeno, ha hecho considerar que, en virtud de la regulación contenida en la norma sexta de la ORDEN EHA/3360/2010, de 21 de diciembre, por la que se aprueban las normas sobre los aspectos contables de las Sociedades Cooperativas del Ministerio de Economía y Hacienda, que viene a derogar la ORDEN ECO/3614/2003, de 16 de diciembre, por la que se aprueban las normas sobre los aspectos contables de las Sociedades Cooperativas, la solución más adecuada para su contabilización sea crear una nueva agrupación en el pasivo del balance con separación de otras partidas, no considerándose dentro del apartado de Fondos Propios, por tener que utilizarse a unos fines concretos.

Así, atendiendo a lo establecido a los efectos en la norma sexta de la mencionada ORDEN EHA/3360/2010, la Contribución «se identifica con los importes que obligatoriamente deben constituirse en las cooperativas con la finalidad de que se apliquen a determinadas actividades que benefician a los socios, trabajadores $y$, en su caso, a la comunidad en general, por lo que su dotación, es un gasto para la cooperativa». Es por ello por lo que el registro contable de dicho fondo se corresponde con una agrupación específica del balance previa al excedente de la Cooperativa denominada «Fondo de Educación, Formación y Promoción», en la medida que son conceptos específicos establecidos al efecto en las leyes de cooperativas que responden a las características de estas sociedades.

La dotación correspondiente al fondo afectará al resultado como un gasto, reflejándose debidamente en la cuenta de pérdidas y ganancias, sin perjuicio de que su cuantificación se realice teniendo como base el propio resultado del ejercicio, y la aplicación de este fondo a su finalidad producirá su baja, registrándose con abono, generalmente, a una cuenta de tesorería.

De esta manera, las operaciones contables serían las siguientes:

La dotación, cargando la cuenta 657 contra la cuenta 148, representativa del fondo:

(657) Dotación al COFIP a (148) COFIP

Si la fuente dotacional derivase de una sanción económica impuesta a un socio: 
(57) Tesorería a (7570) Sanciones impuestas a socios imputables al COFIP (657) Dotación al COFIP a (148) COFIP

El resultado general de la Cooperativa no varía, dado que se compensa una cuenta de ingresos con una de gastos, pero se produce un aumento del COFIP.

En cuanto a su aplicación, la Orden no regula el control y registro de las aplicaciones del fondo, motivo por el que parece lógico concluir que la fórmula más sencilla resultaría la de la contabilización directa, registrando las aplicaciones del fondo directamente contra la cuenta representativa del mismo.

(148) COFIP a (410) Acreedores varios: Curso de formación

Todo ello sin perjuicio de la posibilidad de su eventual contabilización a través de la creación de cuentas específicas, incluyendo tanto partidas de balance como de la cuenta de pérdidas y ganancias, con la correspondiente liquidación «final» al cierre del ejercicio contra la propia cuenta del fondo.

(6232) Servicios exteriores afectados al COFIP a (410) Acreedores varios: Curso de formación

(148) COFIP a (6232) Servicios exteriores afectados al COFIP.

\section{Aplicaciones de la COFIP}

Tal y como hemos señalado con anterioridad, en virtud de la regulación vigente la Cooperativa no tiene poder de disposición sobre esta Contribución, más allá de destinarla a las finalidades de interés público expresamente indicadas, siendo, en consecuencia, inembargable y debiendo figurar en el pasivo del balance.

Es decir, conviene señalar en este mismo sentido que existe una prohibición expresa; la COFIP se configura como irrepartible, tanto durante la vida de la cooperativa, como en caso de disolución y liquidación [art. 98.2.a) de la LCE], que disponen que el remanente de la COFIP se pondrá a disposición del Consejo Superior de Cooperativas de Euskadi. Esta prohibición de reparto de la Contribución, que tiene 
carácter complementario a la inembargabilidad que se le reconoce, es igualmente acorde con el carácter taxativo, al menos en su dicción literal, del listado de fines que la Ley enuncia. Eso puede deducirse también, mediante una interpretación "a contrario», de la ausencia, en nuestra legislación, de excepción alguna al mandato legal de aplicación.

Las posibles aplicaciones o utilizaciones de la Contribución son muy diversas en cuanto a sus fines y destinos, pero pueden subsumirse bajo dos modalidades básicas:

- En forma de inversión: Deben buscarse las fórmulas contables para que se respete el carácter de "patrimonio separado» afectado al cumplimiento de unos determinados fines. Es decir, inversión no entendida como acto mediante el cual se adquieren ciertos bienes con el ánimo de obtener unos ingresos o rentas a lo largo del tiempo, sino como empleo de un capital en algún tipo de actividad o negocio directamente vinculado a alguno de los fines legalmente establecidos para tal Contribución y que veremos más adelante, con el objetivo de mejorar o incrementar los mismos.

- En forma de gasto: Entendida bien como cualquier salida de dinero que la empresa debe pagar para un artículo o por un servicio, o bien como la acción de dar fondos u otros bienes materiales, generalmente por donación, ya sea en términos absolutos (pura) o dependiendo de un acontecimiento (condicional).

Como ya indicábamos, tanto las dotaciones a la Contribución, como las aplicaciones requeridas por el plan y tanto en caso de tratarse de gastos corrientes como de inversiones para el inmovilizado, se reflejarán en la contabilidad social de forma separada y en cuentas que indiquen claramente su afección a dicha Contribución.

Los Estatutos o la Asamblea General deberán fijar las actividades a que ha de destinarse esta Contribución y las líneas básicas de su utilización.

Es por tanto competencia de la Asamblea General «fijar las líneas básicas» de aplicación de la Contribución, siempre respetando el listado de fines que las propias normas establecen. La fijación del plan e igualmente la ejecución de este proyecto de aplicación de la Contribución quedarían en manos de los Administradores - Consejo Rector-, siempre a salvo de la previsión estatutaria específica que encomendase tal tarea a otro órgano, creado por la propia sociedad Cooperativa, dado que no es ésta una atribución que la Ley encomiende, como competencia específica, a los Administradores. 
Por el contrario, la determinación de las directrices básicas de aplicación de la Contribución, no es delegable, dado que según lo establecido por el artículo 31.5 de la LCE, la Asamblea no puede delegar aquellos asuntos que la Ley le encomiende expresamente, como es el caso.

No cabrían por tanto autorizaciones «en blanco» a los Administradores para que procedieran a aplicar la Contribución conforme a sus propios criterios. Aun así, el tenor legal permite que su exigencia se satisfaga con la aprobación de directrices generales de carácter abierto, que posibilitan un amplio margen de maniobra al Consejo Rector, a la hora de ponerlas en práctica.

Como ya se ha dejado señalado que, la LCPE al establecer las líneas básicas de aplicación de la Contribución, se debe respetar la regla de que «se destine a actividades» que cumplan «alguna de las finalidades» que reseña a continuación con carácter alternativo. Más que de cuatro finalidades, cabría hablar de una pluralidad de fines que, sin embargo, pueden agruparse en torno a los inicialmente referenciados tres principios cooperativos que se pueden resumir en educación, intercooperación e interés por la comunidad.

Si bien como anteriormente señalábamos la Exposición de Motivos de la LCPE pretende mediante su Disposición Adicional Cuarta clarificar la naturaleza de los recursos destinados a finalidades por ella estimadas como de interés público, no es menos cierto que en su regulación nada se dice de la naturaleza de esos recursos.

Lo que sí constituye una novedad en este sentido es el reconocimiento expreso de la naturaleza de sus finalidades, que son considerados de interés público, sin que se recoja de forma expresa el efecto que ello tiene en la naturaleza de los recursos en sí mismos.

Se han revisado sus finalidades tratando de compaginar la realidad social cooperativa con el carácter de interés público de las mismas. Así, mediante la modificación del artículo 68 de la LCE, se establecen los fines estimados como de interés público a que pueden destinarse:

1. La formación y educación de sus socios y trabajadores sobre el cooperativismo, actividades cooperativas y otras materias no relacionadas con el puesto de trabajo

Esta directriz consagrada en el artículo 1 de la LCE es, quizás, una de las de mayor trascendencia en el Derecho cooperativo autonómico, al que hace alusión la propia denominación de la Contribución. El principio de educación es inescindible del de promoción, atendiéndose a 
los Principios de la $\mathrm{ACl}$, que establece que deberá existir en la Cooperativa un fondo destinado a impartir la enseñanza de los principios y métodos de la cooperación, tanto en el plano económico como democrático, a sus miembros, ya sean socios o trabajadores asalariados con una vinculación laboral común.

Se ha criticado que otros ordenamientos, incluida la regulación contenida por la LCE con anterioridad a la modificación de la LCPE, extienden los fines de educación a las materias económicas, técnicas o profesionales. Pero se debe reseñar en este sentido que el legislador no sólo ha suprimido de la nueva regulación de la legislación cooperativa autonómica en la materia dichos fines o posibilidades, sino que incluso expresamente ha recogido como materias excluidas las relacionadas con el puesto de trabajo. Es decir, no cabría una lectura integradora que supere una concepción restrictiva en este sentido, tal y como quizás quedaba abierto en la redacción de la Ley 1/1982.

En coherencia con el reconocimiento expreso del interés público de las finalidades, se viene a restringir las posibilidades de destino de la COFIP a la formación, no pudiendo por tanto interpretarse la dicción "actividades cooperativas» como un cajón desastre que legitima cualquier actuación formativa en aspectos técnicos directamente relacionados con el objeto social de la Cooperativa. Como tales «actividades cooperativas» cabría la posibilidad de interpretar aquellas acciones que, por ejemplo, viniendo obligada a desarrollar la propia Cooperativa, constituyen un hecho diferencial de las sociedades clásicas e inherentes a su espíritu, como por ejemplo la efectiva ejecución de la democracia participativa de los socios a través de su participación en la Asamblea General. Lo cual no implica que cualquier actuación llevada a cabo en el marco de la celebración de la Asamblea General tenga cabida en los fines señalados, sino sólo aquellos estricta y directamente vinculados a la organización de la misma, excluyéndose acciones tangenciales tales como facilitar la asistencia de los socios gastos de desplazamiento...-, organizar una comida «popular» para los socios...

El motivo de esta modificación es el hecho de que si bien la formación en aspectos técnicos es precisa en cualquier empresa, en la empresa cooperativa cobra una especial importancia la formación en los valores cooperativos, y, sobre todo, en las actitudes y técnicas que fomentan y asientan la participación democrática en la gestión de la propia Sociedad.

Por otro lado, dentro de las eventuales actuaciones enmarcadas dentro de estos fines, la LCPE establece como grupos de destino sólo a aquellos con una afección directa, es decir, un destino exclusi- 
vamente interno, dirigido tanto a los socios como a los trabajadores asalariados de la misma. En este sentido, la difusión externa quedaría encuadrada entre las posibles actuaciones de los fines más adelante expuestos, dentro del punto tercero, si bien en cierta medida cabría la posibilidad de interpretar que la inclusión de la participación de los trabajadores asalariados, en su condición de no socios - propiedad cooperativizada-, atempera en cierta medida la ausencia de destino exterior.

A continuación, y título orientativo reconociendo la imposibilidad de establecer un numerus clausus de las actuaciones que podrían desarrollarse en cumplimiento de los requisitos y finalidades perseguidas por el legislador mediante la redacción de la norma, podemos señalar algunas aplicaciones concretas de la Contribución en relación a los fines enunciados y que entendemos que la actuación controladora o fiscalizadora de la Administración difícilmente podría negar la adecuación de las actividades que pasamos a exponer con los fines que la LCPE quiere para la Contribución:

- La organización y oferta de actividades destinadas a iniciar, perfeccionar o cualificar en el conocimiento del cooperativismo a colectivos de la propia Cooperativa relacionados o interesados en la materia, tales como cursos de información y formación, cursos de especialización en el conocimiento de la teoría y de la legislación cooperativa, seminarios y conferencias que versen sobre cuestiones de semejante índole...

- La dotación de becas y ayudas para participar en las mismas actividades formativas indicadas, ofertadas por terceros.

- La elaboración o redacción de medios de divulgación cooperativa interna (circulares...).

- Suscripción a publicaciones.

- Creación de infraestructuras y dotación de medios para la formación, fondo de documentación, biblioteca...

- Organización de actividades cooperativas tales como la celebración de la Asamblea General

Quedarían por tanto excluidas dentro de las presentes finalidades todas aquellas actuaciones formativas (organización y participación en cursos, seminarios, jornadas...) dirigidas a personas no socias o trabajadores asalariados de la Cooperativa; cualquier acción formativa cimentada en la formación y educación en aspectos técnicos (de logística, abastecimiento, productivos, comerciales, económico-financieros, contables, organizativos, de innovación...), aun cuando estuviera dirigidos a los grupos de interés anteriormente expuestos; las infraestruc- 
turas y proyectos de I+D; los costes indirectos derivados de la organización de la Asamblea General y reuniones del resto de órganos sociales o equipos de trabajo de la Sociedad, por estimarse que todas ellas forman parte de la propia dinámica socio-empresarial de la empresa, tal y como se deriva de la obligación legal de los socios de asistir a las mismas [art. 22.a) de la LCE].

2. La promoción de las relaciones intercooperativas, incluyendo la cobertura de gastos por la participación en entidades creadas para la promoción, asistencia, dirección común o actividades de apoyo entre cooperativas

En sintonía con otro de los Principios Cooperativos de la $\mathrm{ACl}$ reconocidos genéricamente en el artículo 1 de la LCE, son fines apropiados para la aplicación de la COFIP, en general, todas las actividades que puedan enmarcarse en el principio de intercooperación -las cooperativas sirven a sus miembros más eficazmente y fortalecen el movimiento cooperativo. Trabajando de manera conjunta por medio de estructuras locales, nacionales, regionales e internacionales-, mencionándose expresamente, el fomento de la asistencia técnica y la creación de supraestructuras cooperativas de apoyo. En realidad, toda actividad que, en definitiva, venga a redundar en la promoción de las relaciones intercooperativas, entendidas en el amplio sentido en que las concibe la propia legislación vigente.

Especial consideración merece la posibilidad de satisfacer, con dotaciones a la COFIP, los gastos que se deriven de la participación en cooperativas de segundo grado, de integración a otras entidades que se creen para la promoción, asistencia, dirección común o prestación de actividades de apoyo entre cooperativas. Ello cubriría al entender de esta parte, tanto los gastos derivados de la adhesión a tales entidades en condición de socio - cuotas de ingreso, derrama de pérdidas...-, excluidos los correspondientes al eventual desembolso de las aportaciones a capital (susceptibles de reembolso, en caso de causar baja, y de generar ingresos; distribución de resultados...), como los gastos que deban sufragarse por los servicios recibidos por la cooperativa o en relación a las actividades desarrolladas por aquellas.

Esas concreciones no hacen referencia tan sólo a la promoción de relaciones intercooperativas, sino incluso a su desarrollo y mantenimiento, con lo que tiene cabida cualquier relación entre cooperativas, ya sea de carácter corporativo, de defensa de intereses sectoriales 0 , simplemente, comerciales, siempre que se concreten en la participación 
en una entidad con personalidad jurídica propia que persiga, como señala la LCPE, la promoción, asistencia, dirección común o actividades de apoyo entre las cooperativas. Además, nada establece la LCPE respecto a la necesidad de que dichas entidades deban tener la misma fórmula societaria, aunque sí remarca que deban llevarse a cabo «entre» cooperativas y no "a» cooperativas, destacándose así el papel activo de éstas.

Las posibilidades que pasaremos a reseñar sólo deben cualificarse, para este caso, en relación al fin de intercooperación al que deben dirigirse. La Cooperativa busca con la intercooperación una mejora bien en los resultados empresariales, bien en la defensa de intereses comunes, sectoriales o cooperativos.

Como consecuencia de lo anteriormente expuesto, se estima que entran dentro de los usos de la COFIP en el marco de las presentes finalidades, las siguientes:

- El pago de las cuotas a las entidades asociativas -Federaciones de Cooperativas-, incluidos los gastos derivados de los procesos de creación.

- Apoyo o participación en acciones de promoción de la intercooperación.

- Mantenimiento o prestación de servicios de supraestructuras; gastos de participación de una Cooperativa de primer grado en una de segundo o ulterior grado.

- Los gastos de participación de una Cooperativa en un grupo corporativo, sea o no éste cooperativo, es decir, con independencia de la fórmula societaria que adquiera.

- Los gastos de actividades intercooperativas entre varias cooperativas para realizar actividades conjuntas en áreas determinadas.

- Los gastos o dotaciones realizadas en entidades de promoción cooperativa, léase la Asociación para la Promoción de la Economía Social del País Vasco - APES Euskadi; la Sociedad para la promoción de cooperativas Elkar-Lan, S.Coop.; BIZIKOOP; Promokoop Fundazioa...

- Acciones de investigación directamente encaminadas a la creación o participación en entidad diferente a quienes la integran.

La participación en una nueva entidad de intercooperación llevada a cabo con cargo a la COFIP, condiciona que cualquier resultado de dicha entidad deba ser adscrito a la contabilidad separada de dicha Contribución, con las ventajas e inconvenientes que ello implica.

Por el contrario, se estima que no entran en el marco de las actuaciones desarrollables con cargo al COFIP, las transacciones comercia- 
les habituales entre cooperativas —creación de Uniones Temporales de Trabajo...-; las acciones de relación entre cooperativas; la cesión de la COFIP a otra cooperativa para su disposición libre, a excepción de aquellas entidades creadas expresamente en base a criterios de intercooperación, sean cooperativas (Elkar-Lan, S.Coop.) o no (APES-Euskadi; BIZIKOOP; Promokoop Fundazioa); ...

3. La promoción educativa, cultural, profesional y asistencial, así como la difusión de las características del cooperativismo en el entorno social en que se desenvuelva la cooperativa y en la sociedad en general

Al hilo de lo señalado en relación a la primera de las finalidades, cabe destacar también que parte de las actuaciones encuadradas en la misma podrían ser extrapolables a la presente en cuanto a su repercusión respecto al público — sociedad-en general.

Esta pretensión de «educar» en el cooperativismo, de «enseñar» a la sociedad en general es, tal vez, una formulación arcaica de la finalidad que hoy llamaríamos de «promoción»: informar a la sociedad acerca de la realidad cooperativa, divulgar su propia existencia, sus caracteres y sus logros, como paso previo a su mayor difusión en un entorno conocedor y receptivo.

Pero todos estos campos son muy difíciles de delimitar, porque resulta prácticamente imposible definir y establecer límites a los términos «educativa», «cultural», «asistencial», «profesional»y «divulgación», recogidos por la LCPE, dando continuidad a lo ya regulado en este sentido por la LCE.

Resulta por tanto imposible reseñar aquí la amplitud de posibilidades que la norma ofrece. Prácticamente cualquier actuación que redunde en provecho de la comunidad o de determinados colectivos del entorno susceptibles de asistencia, y no exclusivamente en el interés empresarial de la cooperativa, podría quedar amparada en esta cláusula que se entroncaría con la declaración general que abre la actual Ley sustantiva, en la que se describe como objeto de la sociedad cooperativa el desarrollo de cualquier actividad económica y social, al servicio de sus miembros y atendiendo a la comunidad de su entorno. Adviértase el interés que el hecho de recoger esta norma en las directrices aprobadas por la Asamblea puede revestir, a la hora de aplicar eventuales remanentes de gasto, tal vez de poca entidad, o de justificar actividades que no encuentren acople perfecto en el apartado inmediatamente anterior. 
Podemos decir que estamos hablando de desarrollo personal y colectivo en búsqueda de la mejora de la calidad de vida de los ciudadanos, de una forma solidaria, siendo la Cooperativa benefactor del exterior, sin que dichas acciones tengan un objetivo inmediato «intracooperativo» como ocurre en el caso de los fines anteriormente descritos. ${ }^{15}$

Así, distinguiendo entre las actuaciones encuadradas dentro de las presentes finalidades, y como simple ejemplo que en caso alguno puede ni pretende ser númerus clausus, se estima que:

\subsection{ENTRE LAS ACTIVIDADES DE DIFUSIÓN CABRÍAN}

— La realización de campañas divulgativas en los medios de comunicación social.

- La edición de publicaciones, folletos u otros medios publicitarios, siempre que aborden la temática señalada.

- La edición, bajo cualquier fórmula audiovisual, de programas o contenidos formativos especializados en la materia.

- La organización de concursos, proyectos de actos culturales o lúdico-festivos $u$ otros con finalidad meramente divulgativa, es decir, excluyéndose aquellas actuaciones que, teniendo por objetivo la publicidad de la empresa (marca...), sean propias de una política de marketing.

\subsection{ENTRE LAS ACTIVIDADES DE PROMOCIÓN EDUCATIVA CABRÍAN}

- La organización o subvención a la organización o asistencia a congresos, simposiums, jornadas o visitas de carácter técnico.

- El apoyo a la presencia y participación de las Cooperativas en ferias, muestras, certámenes u otras manifestaciones similares.

- La ayuda a la investigación y documentación sobre cooperativismo.

- La edición del material correspondiente.

- Al consumerismo, en general, en las Cooperativas de Consumo.

Destacar también que los gastos de conservación, reparación o amortización de los bienes afectados a estos fines se consideran costeables en base a la Contribución.

15 Gómez De la Iglesia, R. «El Fondo de Educación y Promoción Cooperativa». Editado por la Federación de Cooperativas de Trabajo Asociado de Euskadi. Vitoria-Gasteiz 1994. 
- Dotaciones a Universidades o sus Centros de Investigación.

- Dotaciones a los Centros de Formación en cualquiera de los grados.

- Becas para investigadores para la mejora de los sistemas educativos.

- Becas para ayudar a estudiantes a sufragar parte de sus gastos fuera de su domicilio habitual.

\subsection{ENTRE LAS ACTIVIDADES DE PROMOCIÓN CULTURAL CABRÍAN}

- Ayudas para aulas de cultura de los municipios en que tenga implantación la Cooperativa.

- Ayudas para que los vecinos de la localidad de la Cooperativa visiten museos, vayan al teatro, ópera, cine, etc.

- Ayudas a artesanos para que difundan su oficio en determinadas localidades donde tenga su ámbito de influencia la Cooperativa.

- Ayudas para cofinanciar actos o ferias de carácter cultural.

- Ayudas para la formación en TICs.

\subsection{ENTRE LAS ACTIVIDADES DE PROMOCIÓN PROFESIONAL CABRÍAN}

Promoción profesional no inexcusablemente ligada a la escuela o a la enseñanza reglada, sino que cabría también todo el apoyo a la formación ocupacional, a proyectos de información y de orientación laboral, de promoción de nuevas empresas...

- Ayudas para realizar cursos que mejoren los conocimientos/habilidades de las personas.

- Ayudas para la adquisición de medios informáticos que puedan utilizar las personas socias o trabajadoras por cuenta ajena, para su utilización para su promoción profesional.

\subsection{ENTRE LAS ACTIVIDADES DE PROMOCIÓN ASISTENCIAL CABRÍAN}

- Ayudas para personas con discapacidades en la Cooperativa o en la localidad —entorno- donde está enclavada.

- Ayudas para centros de día, residencias, etc.

- Ayudas para operaciones o intervenciones quirúrgicas no atendidas por la red de la Seguridad Social/Osakidetza.

- Ayudas para compra de libros de enseñanza.

- Ayudas para los gastos de la guardería de los niños.

- Ayudas para los gastos de cuidado de familiares.

- Ayudas para colectivos desfavorecidos. 


\section{La promoción del uso del euskera}

Aspecto muy destacable dentro del presente punto es la creciente repercusión que el legislador ha querido otorgar como posible actuación a desarrollar en el marco de la COFIP a favor de la promoción del euskera. Resulta evidente que ya con la regulación anterior contenida en la LCE las acciones encaminadas a la promoción del euskera tenían cabida en el Fondo correspondiente en el marco fundamentalmente de las actividades culturales, pero no es menos cierto que su actual expresa reminiscencia legislativa le confiere no sólo mayor seguridad/garantía jurídica por denominarlo de alguna manera, sino muchísima mayor proyección práctica.

Dando continuidad a la dinámica anteriormente seguida, señalar también como posibles actividades de promoción del euskera cabrían, entre otros, las siguientes:

- Diseño e implementación de planes de euskera, tanto en la propia Cooperativa como para el colectivo de socios, trabajadores asalariados, proveedores, clientes... y en general con terceras personas con las que se relacione la Sociedad en el ámbito de la Comunidad Autónoma del País Vasco.

- Organización de actos culturales en el marco del euskera.

- Ayudas a la organización y participación en actos de promoción del euskera: Korrika, Ibilaldia —Ikastolas—, Araba Euskaraz, ...

5. La promoción de nuevas empresas cooperativas mediante aportaciones dinerarias a una entidad sin ánimo de lucro promovida por el movimiento cooperativo vasco

Al igual que en el supuesto de la promoción del euskera, se trata de una finalidad que si bien con la regulación anterior se estima que también entraba dentro del marco de las eventuales actividades a desarrollar con cargo al Fondo, la nueva regulación fruto de la ya referenciada modificación legislativa ha traído consigo la expresa incorporación de la misma atendiendo fundamentalmente al papel cada vez más relevante que vienen desempeñando en la promoción de nuevas empresas cooperativas entidades tales como por ejemplo APES-Euskadi; BIZIKOOP; Elkar-Lan, S.Coop. y Promokoop Fundazioa.

En virtud de cuanto antecede, cabe destacar también que de la propia dicción de la norma se deriva el necesario cumplimiento de varios requisitos, como son: 
a) En relación al benefactor:

- Que la actuación consista en el desembolso de una aportación dineraria.

b) En relación a las entidades beneficiarias:

- Que se trate de una entidad. Es decir, quedan excluidas las personas físicas, limitándose por tanto a personas jurídicas, con independencia de la fórmula societaria que posean.

- Que tengan entre sus objetivos la promoción de nuevas empresas cooperativas.

- Que se trate de entidades sin ánimo de lucro. Para la consideración como tales, se requiere el cumplimiento de una serie de requisitos que varían según la fórmula societaria que ostenten. Por ejemplo, mientras las Fundaciones lo son por naturaleza, es decir, se trata de una característica inherente a su propia formulación societaria, las Cooperativas vienen obligadas al cumplimiento de los siguientes requisitos:

- Que los resultados positivos que se produzcan en un ejercicio económico no podrán ser distribuidos entre sus socios.

- Que las aportaciones de los socios al capital social, tanto obligatorias como voluntarias, no podrán devengar un interés superior al interés legal del dinero, sin perjuicio de la posible actualización de las mismas.

- El carácter gratuito del desempeño de los cargos del Consejo Rector, sin perjuicio de las compensaciones económicas procedentes por los gastos en los que puedan incurrir los Consejeros en el desempeño de sus funciones.

- Que las retribuciones de los socios trabajadores, o, en su caso, de los socios de trabajo y de los trabajadores por cuenta ajena no podrán superar el ciento cincuenta por ciento de las retribuciones que, en función de la actividad y categoría profesional, establezca el Convenio colectivo aplicable al personal asalariado del sector.

- Que sean entidades promovidas por el movimiento cooperativo vasco, entendido como tal tanto las propias cooperativas, como cualquier fórmula de asociacionismo libre y voluntario que pudieran llevar a cabo aquéllas (art. 163 de la LCE). 
6. La formación y educación de las personas socias y trabajadoras para el fomento en las sociedades cooperativas de una política efectiva para avanzar hacia la igualdad de mujeres y hombres

Finalidad que irremediablemente debemos ligar tanto al $\mathrm{V}$ Principio Cooperativo, en cuanto al aspecto educacional y formativo, como, fundamentalmente, a los valores cooperativos de igualdad y equidad aprobados por la $\mathrm{ACl}$. No podemos ser ajenos al hecho de que la consecución del objetivo perseguido por el avance hacia la igualdad de mujeres y hombres no puede resultar de una actuación concreta y puntual, sino que requiere, necesariamente, de una ardua labor educacional implementada en el sistema: tanto educativo, como empresarial.

Actividades tales como la implementación de planes de igualdad, y que pueden ser ejecutadas bien sea de manera directa por la propia Cooperativa, o a través de consultoras externas especializadas.

Y ello porque cabe subrayar que la LCE recoge (extrapolando la regulación contenida en la Ley 6/2008) de manera expresa la posibilidad de que las Cooperativas puedan llevar a cabo todas las finalidades descritas con anterioridad tanto de manera directa como indirecta, es decir, canalizándose el destino de la Contribución a través de aportaciones dinerarias a entidades sin ánimo de lucro o a alguna de las entidades de intercooperación citadas en el punto 2 .

En todo caso, y como es lógico, dicha entrega a favor de entidades intermediarias estará condicionada al mantenimiento del destino de las mismas a las finalidades de interés público expuestas en la presente, sea a través bien de actuaciones de la propia entidad intermediaria o bien de otras personas físicas o jurídicas a las que dicha entidad destine los recursos recibidos.

A tenor de cuanto señalábamos al inicio de la exposición de las presentes finalidades habilitadas por la LCE, diremos también que la imposibilidad práctica de delimitar una relación concreta de actuaciones apreciadas como ajustadas a derecho de las que no se ve acrecentada por el hecho de que la actividad desarrollada por cada Cooperativa también tiene afección sobre las mismas.

Así, se estima que, por ejemplo, la compra de un software -inversión en inmovilizado- que tenga por objeto la promoción del euskera por parte de la Cooperativa sí se ajustaría a las finalidades de la COFIP enmarcadas como actuaciones de promoción del euskera, siempre y cuando la citada Cooperativa no tuviera entre las actividades de su objeto social el impulso del euskera.

En este mismo sentido, cabe destacar también que cualquier actuación de promoción y difusión que se lleve a cabo con cargo a las dota- 
ciones de la Contribución debe tener por objeto en sí misma la propia promoción, bien sea cultural, asistencial..., y difusión del cooperativismo, desmarcándose claramente de otras finalidades vinculados a la actividad de la Cooperativa y su mejora; léase, por ejemplo, contratos de patrocinio y publicidad que busquen la mejora de la imagen de la marca o del producto al amparo de la aplicación de las citadas dotaciones de la Contribución. Al hilo de lo señalado, es evidente que en ocasiones resulta no sólo harto complicado determinar o delimitar la línea que distingue entre la promoción ajustada a derecho y la mera publicidad, sino incluso un ejercicio de apreciación subjetiva y personal.

Una misma actuación de promoción llevada a cabo con cargo a la COFIP puede tener lecturas distintas en relación al cumplimiento o no de las finalidades legalmente establecidas a los efectos. Por ejemplo, la aportación de una ayuda a una entidad deportiva de la localidad en la que esté ubicada la sede social de la Cooperativa parece evidente que, por sí misma, no implica vulneración de la normativa vigente, pero ¿y cuándo a cambio de la citada aportación la entidad deportiva luce en sus camisetas publicidad de la Sociedad? ¿Tendría la misma repercusión y consideración jurídica si el bien producido por la Cooperativa fuera finalista - por ejemplo, colchones o asesoramiento fiscal- o no - componentes para vehículos o asesoramiento en internacionalización empresarial? Es decir, ¿si fuera susceptible o no de consumo directo por parte de los receptores de esa «publicidad»? Se estima que en el primero de los supuestos la actuación de la Cooperativa tiene una repercusión comercial evidente por estar dirigida a potenciales clientes, no así en el segundo de los casos en el que la promoción «cultural» del entorno parece el objetivo final. Es por ello por lo que en ocasiones se presume razonable un tratamiento diferenciado de las actuaciones realizadas por las Cooperativas respecto al cumplimiento o no de las finalidades legalmente previstas para la aplicación de las cantidades dotadas a la COFIP, lo que no hace más que dificultar, más aún si cabe, la concreción de los posibles destinos de la Contribución enmarcados en estas finalidades.

Por último, reseñar también que gran número de las finalidades aquí recogidas forman parte de la Responsabilidad Social Empresarial (RSE), es decir, la contribución activa y voluntaria al mejoramiento social, económico y ambiental por parte de las empresas y que va más allá del mero cumplimiento de la legislación de referencia por su formulación societaria y actividad.

Para finalizar, cabe destacar también otro aspecto que se mantiene en idénticos términos a los regulados por la Ley 6/2008, como ya se advertía, y que tiene gran trascendencia práctica respecto a las 
aplicaciones de las dotaciones a la Contribución. En virtud de la citada regulación las Cooperativas no pueden posponer la aplicación de las mencionadas cantidades más allá del ejercicio en el que se hubiera aprobado la distribución del excedente; es decir, el siguiente a aquel en el que se generaron, viniendo obligadas a entregar las cantidades de la Contribución que no se hubieran destinado a las finalidades de interés público indicadas dentro del ejercicio económico siguiente al de la aprobación de la distribución de los excedentes a favor de una o varias entidades sin ánimo de lucro que será la encomendada de destinarlas a las finalidades de interés público establecidas para esta Contribución.

Resulta reseñable el hecho de que las Cooperativas pierden la libertad o capacidad decisoria que mantenían hasta la entrada en vigor de la Ley 6/2008 sobre la aplicación de aquellas cantidades dotadas y no aplicadas a lo largo del ejercicio siguiente en el que se generaron, previa cumplimiento del requisito de su materialización en títulos de la Deuda Pública de la Comunidad Autónoma del País Vasco (segundo párrafo del artículo 68.5 de la Ley 4/1993, modificada por la LCPE, manteniendo la actual LCE esta última modificación).

De esta manera, si bien hasta la entrada en vigor de la LCPE las cantidades dotadas y no aplicadas podían quedarse en el balance de las Cooperativas ${ }^{16}$, a partir de ésta la COFIP tiene fecha límite dentro del citado balance. Es decir, si no han sido destinadas a lo largo del ejercicio en el que se aprobó la distribución de excedentes, dentro del ejercicio siguiente debe salir obligatoriamente del patrimonio de la Cooperativa.

Atendiendo a todo ello, parece evidente deducir que lo que pretendía el legislador mediante aquella modificación era la superación de la pasividad que hasta la fecha se venía adueñando de gran número de Cooperativas en relación a la aplicación práctica de las cantidades dotadas a tales fines, y que venían arrastrándose -acumulándose- durante años alcanzando en ocasiones hasta la fecha de su efectiva disolución y liquidación. Así, procura el uso o empleo activo de las mencionadas cantidades mediante el mandato legal de su obligatoria transferencia por parte de la Cooperativa que por imposibilidad o por indolencia no hubiere aplicado íntegramente las mimas, a favor de una entidad sin ánimo de lucro que, en todo caso, vendrá obligada a garantizar en

16 La LCPE no establecía nada en relación al régimen de aquellas cantidades que, dotadas en base a los resultados de ejercicios anteriores y por consiguiente sujetas a la regulación anterior, a la fecha de su entrada en vigor permaneciesen aún pendientes de aplicación (en el balance). 
todo momento su destino acorde a las finalidades legalmente establecidas y referidas.

Si bien también es cierto que la citada regulación, que mantiene la LCE vigente, no establece plazo alguno para que dicha aplicación sea llevada a cabo por la entidad que hubiere resultado adjudicataria de las citadas cantidades pendientes de aplicación, limitándose a establecer el plazo de entrega de las mismas a favor de la entidad sin ánimo de lucro a la que se le encomiende la aplicación de las mismas dentro del ejercicio económico siguiente a aquel en el que se aprobó la distribución de los excedentes, parece lógico deducir que el plazo más prudente sería el que comprende el ejercicio en el que se hubiera llevado a cabo la transferencia, prorrogándose de esta manera el plazo otorgado a los efectos a la propia Cooperativa.

\section{Eventual régimen especial de aplicabilidad del fondo derivado de la normativa COVID-19}

No se puede obviar en el marco del presente estudio la especial referencia que la normativa aprobada con motivo de la COVID-19 realizó al Fondo de Educación y Promoción Cooperativa y su aplicabilidad.

Así, el Real Decreto-ley 15/2020, de 21 de abril, de medidas urgentes complementarias para apoyar la economía y el empleo (BOE 22 de abril de 2020), dispone en su art. 13, como medida para facilitar el ajuste de la economía y proteger el empleo, la flexibilización, de forma temporal y extraordinaria, del uso del Fondo de Promoción y Educación de las Cooperativas con la finalidad de paliar los efectos de la COVID-19.

En este sentido, desarrolla la medida en los términos siguientes:

1. Durante la vigencia del estado de alarma declarado por el Real Decreto 463/2020, de 14 de marzo, por el que se declara el estado de alarma para la gestión de la situación de crisis sanitaria ocasionada por el COVID-19 y sus posibles prórrogas y hasta el 31 de diciembre de 2020, el Fondo de Educación y Promoción Cooperativo de las cooperativas regulado en el artículo 56 de la Ley 27/1999, de 16 de julio, de Cooperativas, podrá ser destinado, total o parcialmente, a las siguientes finalidades:

a) Como recurso financiero, para dotar de liquidez a la cooperativa en caso de necesitarlo para su funcionamiento. A estos efectos, el Fondo de Educación y Promoción Cooperativo destinado a esta finalidad, deberá ser restituido por la cooperativa con, al menos, el 30 \% de los resultados de libre disposición que se generen cada año, 
hasta que alcance el importe que dicho Fondo tenía en el momento de adopción de la decisión de su aplicación excepcional y en un plazo máximo de 10 años.

b) A cualquier actividad que redunde en ayudar a frenar la crisis sanitaria del COVID-19 o a paliar sus efectos, bien mediante acciones propias o bien mediante donaciones a otras entidades, públicas o privadas.

2. Durante la vigencia del estado de alarma declarado por el Real Decreto 463/2020, de 14 de marzo, o de cualquiera de sus prórrogas, el Consejo Rector asumirá la competencia para aprobar la aplicación del Fondo de Educación o Promoción en los términos previstos en el apartado 1, cuando por falta de medios adecuados o suficientes la Asamblea General de las sociedades cooperativas no pueda ser convocada para su celebración a través de medios virtuales. La asunción excepcional por parte del Consejo Rector de esta competencia se extenderá hasta el 31 de diciembre de 2020 cuando la protección de la salud de las socias y socios de la cooperativa continúe exigiendo la celebración virtual de la Asamblea General de la sociedad cooperativa y esta no sea posible por falta de medios adecuados o suficientes.

3. A estos exclusivos efectos, no será de aplicación lo dispuesto en los artículos 13.3 y 19.4 de la Ley 20/1990, de 19 de diciembre, sobre Régimen Fiscal de las Cooperativas. Por tanto, el Fondo de Formación y Promoción Cooperativo que haya sido aplicado conforme a la letra a) del apartado 1 del presente artículo, no tendrá la consideración de ingreso para la cooperativa.

Se estima oportuno advertir a este respecto, en primer lugar, la duda sobre la eventual aplicabilidad de la medida a las Cooperativas a las que se regularan por la legislación autonómica vasca. Y ello porque el propio Real Decreto-ley hace referencia expresa al fondo regulado en el art. 56 de la Ley 27/1999, de 16 de julio, de Cooperativas, que resulta de aplicación a las Cooperativas ubicadas en territorio sin legislación autonómica propia y, con carácter subsidiario, a las Cooperativas ubicadas en territorio que, sí teniendo legislación autonómica propia, no tuviera la citada materia desarrollada. Hecho que viene refrendado además por la remisión en el apartado 3 del artículo a la Ley 20/1990, de 19 de diciembre, sobre Régimen Fiscal de las Cooperativas. En el caso concreto que nos ocupa no nos encontramos ante ninguno de los supuestos expuestos, por cuanto:

a) La Comunidad Autónoma del País Vasco tiene arrogada dicha competencia desde 1982 (Ley 1/1982, de 11 de febrero, sobre Cooperativas) y, en la actualidad, a través de la Ley 11/2019, de 20 de diciembre de cooperativas de Euskadi; 
b) Ley que desarrolla además como fondo equiparable al dispuesto por la Ley 27/1999, la Contribución para la educación y promoción cooperativa y otros fines de interés público (art. 72);

c) Tampoco resulta de aplicación la citada la Ley 20/1990, de 19 de diciembre, sobre Régimen Fiscal de las Cooperativas a la que expresamente se remite la norma, por cuanto el particular régimen fiscal de la Comunidad Autónoma del País Vasco hace que el Gobierno de cada Territorio Histórico (Diputaciones Forales) cuente con competencia fiscal a tales efectos, habiéndola todos ellos desarrollado la misma. ${ }^{17}$

Si bien parece lógico concluir que era voluntad del legislador el de la regulación de la aplicabilidad de la medida extraordinaria en todo el territorio estatal, obviando el ámbito competencial de las Comunidades Autónomas en materia cooperativa en virtud de cuanto dispone el art. 148 de la Constitución, todo ello bajo el paraguas del «mando único» arrogado por el Gobierno Central, no lo es menos que la literalidad de la dicción contenida en la norma obliga como mínimo a la reflexión y duda jurídica sobre su aplicabilidad para las Cooperativas reguladas por la ley vasca. Es decir, que para el supuesto de que hubiera sido aquélla la voluntad del ejecutivo, la redacción se estimaría sensiblemente mejorable.

En cualquier caso, y expuesto lo anterior, no se puede más que mostrar la sorpresa de quien suscribe ante la medida adoptada por la Administración central en este sentido, por la poca repercusión económico-financiera que, inicialmente, debiera derivarse de la misma. Y ello porque tanto en la propia regulación estatal del fondo (art. 56.6) como en la autonómica (art. 72.5) se establece expresamente la obligatoriedad de la disposición de las cantidades dotacionales del mismo durante el ejercicio siguiente. Es decir, las cantidades destinadas a dicho fondo en estricto cumplimiento de la legislación vigente durante el ejercicio 2018 deberían haber sido dispuestas durante el 2019, de manera que la Cooperativa estuviera a uno de enero de 2020 sin dotación alguna en dicho fondo. Todo ello sin perjuicio de las posibilidades contenidas por la ley estatal, relativas a la materialización de las citadas cantidades no dispuestas en plazo en cuentas de ahorro, en

17 Básicamente:

Norma Foral 16/1997, de 9 de junio, sobre régimen fiscal de las cooperativas de Araba.

Norma Foral 6/2018, de 12 de diciembre, sobre régimen fiscal de cooperativas del Territorio Histórico de Bizkaia.

Norma Foral 2/1997, de 22 de mayo, de régimen fiscal de las cooperativas de Gipuzkoa. 
títulos de la Deuda Pública o títulos de Deuda Pública emitidos por las Comunidades Autónomas.

Consecuentemente, en la práctica se observan tres posibles supuestos:

a) Cooperativas sin dotación alguna en el fondo señalado y, por lo tanto, sin posibilidad de beneficiarse de la medida extraordinaria;

b) Cooperativas que, en estricto cumplimiento de la legislación vigente, hubieran venido llevando a cabo en tiempo y forma la disposición de las cantidades dotaciones del fondo, pudiendo beneficiarse de la medida extraordinaria por tanto sólo respecto a las cantidades dotadas durante el ejercicio 2019, dado que las correspondientes a los ejercicios anteriores se encontrarían ya dispuestas. Consecuentemente, la repercusión económicofinanciera de la medida resultaría meramente circunstancial, atendiendo a las cantidades dotacionales del fondo durante un ejercicio;

c) Cooperativas que, habiendo incumplido el mandato legal de la disposición de las cantidades dotacionales del fondo durante el ejercicio siguiente, hubieran acumulado (de ejercicios anteriores) cantidades importantes en dicho fondo, hasta el punto de que la medida extraordinaria adoptada por la Administración pudiera resultar económica y financieramente trascendente para la empresa. Reflexión que adquiere especial relevancia en lo que respecta a las cooperativas vascas, por cuanto la legislación vigente ni tan siquiera posibilita la acumulación de cantidades dotaciones en dicho fondo durante el transcurso de los ejercicios, obligando a la empresa a la entrega del importe de la referida contribución que no se hubiera destinado a las finalidades de interés público indicadas a favor de entidades sin ánimo de lucro para su ulterior destino a las mismas finalidades (art. 72.5).

Análisis de los supuestos de hecho que nos lleva a la irremediable conclusión de que la medida económica aprobada por la Administración resulta especialmente beneficiosa, fundamentalmente, para aquellas Cooperativas vascas que hubieran venido incumpliendo sistemáticamente con sus obligaciones en cuanto a la disponibilidad de las cantidades dotacionales del fondo, en contra de aquéllas otras que sí hubieran procurado el cumplimiento estricto de la disposición legal.

De esta manera, y haciendo una interpretación posibilista de la aplicación de la regulación contenida en el Real Decreto-ley 15/2020 referenciado también para las cooperativas vascas, a las finalidades 
previamente expuestas y desarrolladas podríamos ampliar, siempre con límite temporal para su disposición de hasta el próximo 31 de diciembre de 2020, las siguientes:

- Como tesorería - liquidez- de la Cooperativa cuando el mantenimiento de la actividad ordinaria de la misma así lo requiriera.

- Cuando el destino otorgado a dichas cantidades tuviera como objetivo frenar la crisis sanitaria de la COVID-19 o a paliar sus efectos, ya fuera de manera directa, o de manera indirecta, mediante donaciones.

La particularidad deriva del hecho de que la aplicación extraordinaria destinada a frenar la crisis sanitaria o paliar sus efectos no requiere restitución de los importes aplicados, sí en cambio la llevada a cabo como recurso financiero para dotar de mayor liquidez a la empresa para su mantenimiento, que exige la restitución del importe íntegro aplicado mediante la dotación de, al menos, el 30\% de los resultados positivos de cada ejercicio, dentro del plazo máximo de 10 años. Obligación de la que se deriva la duda, al menos a quien suscribe, de qué ocurre si en el plazo de los 10 años no se produce la restitución íntegra de las cantidades aplicadas a aquella finalidad extraordinaria, a pesar del cumplimiento de la dotación mínima del $30 \%$ establecida, y la competencia fiscalizadora tanto del Consejo Superior de Cooperativas de Euskadi, en virtud de la competencia ya citada contenida en el art. 98.2.a) de la LCE, en los procesos de liquidación (distribución del haber social) societaria como, sobre todo, de la Hacienda Foral correspondiente. Cuestión que, en todo caso, no es objeto del presente estudio, sin perjuicio del interés que sobre la misma se aprovecha para advertir aquí. Todo ello sin perjuicio de lo a continuación expuesto.

\section{Consecuencias de la inobservancia del régimen de la COFIP}

\subsection{Administrativas}

Según los puntos a) y b) del artículo 159.2 de la LCE, son infracciones muy graves tanto no destinar a la COFIP los porcentajes mínimos de los excedentes disponibles, como no aplicar las cantidades dotadas a la COFIP a los fines indicados por la propia Ley.

Así, en virtud del régimen sancionador establecido, las infracciones muy graves se sancionarán: 
- Con multa de 3.000 a 30.000 euros (art. 160.1 de la LCE): La determinación de la multa se graduará como mínimo, medio o máximo, atendiendo a su importancia y consecuencias económicas y sociales, a la eventual concurrencia de la mala fe, falsedad, reincidencia, graduándose en tal caso como máximo, y la capacidad económica o volumen de operaciones de la Cooperativa (art. 160.2 de la LCE).

La citada responsabilidad administrativa prescribirá a los seis meses a partir de la fecha en la que la Administración Pública tuvo conocimiento de la comisión de la infracción, y, en todo caso, a los 2 años de que la misma hubiera tenido lugar (apartados 3 y 4 del art. 160de la LCE).

$\mathrm{O}$, en su caso,

- Descalificación de la Cooperativa (arts. 160.1 y 161 de la LCE): La comisión de cualesquiera infracciones calificadas como muy graves podrán ser causas de descalificación de una Cooperativa, cuando provoquen o puedan provocar importantes perjuicios económicos o sociales, o que supongan vulneración reiterada - la anteriormente definida reincidencia - esencial de los Principios Cooperativos [art. 161.1.a) de la LCE], como sería el caso, tal y como se ha venido exponiendo a lo largo del presente informe.

La descalificación, una vez sea firme bien por resolución administrativa o, en su caso, por ratificación vía judicial de la misma, surtirá efectos registrales de oficio e implicará que la Cooperativa deba disolverse o transformarse en el plazo de 6 meses desde que fuera ejecutiva la resolución administrativa, quedando forzosamente disuelta una vez transcurrido dicho plazo. (Art. 161.4 de la LCE)

\subsection{Fiscales}

A las consecuencias administrativas anteriormente descritas se sumarían también las que pudieran derivarse de la regulación del régimen fiscal de las Cooperativas contenida en

- Norma Foral 16/1997, de 9 de junio, sobre Régimen Fiscal de las Cooperativas de Araba (en adelante N.F. de Araba),

- Norma Foral 6/2018, de 12 de diciembre, sobre régimen fiscal de cooperativas del Territorio Histórico de Bizkaia.

— NORMA FORAL 2/1997, de 22 de mayo, sobre Régimen Fiscal de las Cooperativas de Gipuzkoa (en adelante N.F. de Gipuzkoa). 
Así, se establece que será causa de pérdida de la condición de Cooperativa fiscalmente protegida aplicar cantidades de la Contribución a finalidades distintas a las previstas por la Ley. (arts. 12.3, 12.3 y 12.3, respectivamente, de las Normas Forales de Araba, Bizkaia y Gipuzkoa).

Consecuentemente, dicha vulneración conllevaría también, además de las consecuencias administrativas ya expuestas, la pérdida de los beneficios fiscales de las que pudiera estar disfrutando la Cooperativa, y que en virtud de la regulación contenida en los artículos 26 y 27 de la N.F. de Araba, 38 y 39 de la N.F. de Bizkaia y arts. 26 y 27 de la N.F. de Gipuzkoa, básicamente podrían resumirse en:

Cooperativas protegidas:

— Exención en el Impuesto sobre Transmisiones Patrimoniales y Actos Jurídicos Documentados, respecto a los actos siguientes

- Los actos de constitución, ampliación de capital, fusión y escisión.

- La constitución y cancelación de préstamos, incluso los representados por obligaciones.

- Las adquisiciones de bienes y derechos que se integren en la Contribución para el cumplimiento de sus fines.

- Aplicación de un tipo impositivo inferior en el Impuesto sobre Sociedades.

— Libertad de amortización de los elementos de activo fijo

- Bonificaciones en los siguientes Tributos Locales:

- Impuesto de Actividades Económicas.

- Impuesto sobre Bienes Inmuebles correspondiente a los bienes de naturaleza rústica.

Cooperativas especialmente protegidas:

- Exención en el Impuesto sobre Transmisiones Patrimoniales y Actos Jurídicos Documentados, para las operaciones de adquisición de bienes y derechos destinados directamente al cumplimiento de sus fines sociales y estatutarios.

— Bonificación del 50\% de la cuota íntegra en el Impuesto sobre Sociedades.

Además, en relación a las reglas especiales aplicables en el Impuesto sobre Sociedades, y más concretamente en cuanto a la determinación de la Base Imponible, señalar también que tienen la consideración de gastos deducibles -arts. 16 y 17 de la N.F. de Araba, arts. 
15 y 16 de la N.F. de Bizkaia y arts. 16 y 17 de la N.F. de Gipuzkoaaquellas cantidades que las Cooperativas destinen, con carácter obligatorio, a la COFIP, siempre que, entre otros, se cumplan los siguientes requisitos:

- La cuantía deducible de la dotación a la COFIP no podrá exceder en cada ejercicio económico del $30 \%$ de los excedentes netos del mismo.

La Contribución se aplicará conforme al plan que apruebe la Asamblea General de la cooperativa.

- Las dotaciones a la COFIP, así como las aplicaciones que requiera el plan (que se circunscriben a gastos corrientes, dado que como señalábamos, la regulación vigente mantiene la imposibilidad de la inversión en inmovilizado -deuda pública), se reflejarán separadamente en la contabilidad social, en cuentas que indiquen claramente su afectación a dicho Contribución.

- Cuando en cumplimiento del plan no se gaste o invierta en el ejercicio siguiente al de la dotación la totalidad aprobada, el importe no aplicado deberá entregarse a una entidad sin ánimo de lucro para que sea ésta la que destine las cantidades pendientes a los fines legalmente establecidos.

- La aplicación de la COFIP a finalidades distintas de las aprobadas dará lugar, sin perjuicio de la pérdida de la condición de fiscalmente protegida, a la consideración como ingreso del ejercicio en que aquélla se produzca como indebidamente aplicado.

Un eventual acuerdo de la Asamblea General que no respetase las previsiones legales acerca de los supuestos en que la dotación a la COFIP es obligatoria, acerca de los porcentajes a destinar a aquél y acerca de los fines a que debe encaminarse su gasto sería nula por contraria a la Ley (art. 41.1 de la LCE, sin perjuicio de su eventual subsanación en los términos previstos en el apartado 2 del citado artículo) y, consecuentemente, podría ser impugnada por cualquier socio, los administradores, los miembros de la Comisión de Vigilancia, en su caso, y por cualquier tercero con interés legítimo, caducando la misma en el plazo de un año desde la fecha de adopción del acuerdo o su inscripción registral, si fuera inscribible (apartados 3 y 4 del art. 41 de la LCE).

En este mismo sentido, no quisiéramos finalizar la presente sin apuntar, aunque sólo sea con mero carácter informativo, dado que no es éste el objeto del estudio, que la dotación de la COFIP y la ejecución del gasto por los administradores - Consejo Rector y, en su caso, el di- 
rector general - de la Cooperativa de manera contraria a la Ley o a los mandatos de la Asamblea General implicaría:

- un supuesto evidente de responsabilidad de los Administradores de la Cooperativa ${ }^{18}$, quienes, no debe obviarse, responderán solidariamente de los daños que causen por actos contrarios a la Ley o a los Estatutos Sociales o realizados sin la diligencia debida, la cual deberá estimarse con más o menos rigor en función del carácter retribuido o no del cargo (arts. 50 y 51 de la LCE) ${ }^{19}$, $y$, en su caso,

- un supuesto de responsabilidad penal conjunta de la propia Cooperativa ${ }^{20}$ y los administradores que pudiera derivarse - delitos fiscales...- en virtud de la regulación contenida en la Ley Orgánica 5/2010, de 22 de junio, por la que se modifica la Ley Orgánica 10/1995, de 23 de noviembre, del Código Penal(BOE de fecha 23 de junio; n. $^{\circ}$ 152). Se recuerda en este sentido que en tales supuestos las sanciones pueden llegar a resultar sensiblemente más gravosas que las expuestas anteriormente, tanto a título colectivo (Cooperativa), como individual o personal (administradores).

\section{Bibliografía}

ALZOLA, I. y ESNAOLA, J.M.: «Régimen económico: los fondos sociales obligatorios», Manual de derecho de Sociedades Cooperativas. Editado por el Consejo Superior de Cooperativas de Euskadi y dirigido por Santiago Merino Hernández. Vitoria-Gasteiz 2007.

CRACOGNA, D. 2019. «El Principio De autonomía E Independencia En La declaración Sobre La Identidad Cooperativa». Boletín de la Asociación Internacional de Derecho Cooperativo, n. ${ }^{\circ} 55$ (diciembre), 19-34. https://doi. org/10.18543/baidc-55-2019pp19-34.

18 Ver Morillas Jarillo, M.J.: »La responsabilidad de los administradores de las sociedades cooperativas: mosaico legal e interpretación judicial». CIRIEC-España, Revista Jurídica de economía social y cooperativa, n. ${ }^{\circ} 28$. Valencia 2016. Pp. 97-154.

19 Ver Gondra Elgezabal, G.: «Administratzaileen erantzukizuna Euskadiko Gizarte Ekonomiako enpresentan: Bereziki Kooperatiba Elkarteetan». Revista Vasca de Economía Social; n. ${ }^{\circ}$ 1. Editado por la Universidad del País Vasco. (UPV/EHU). Donostia-San Sebastián 2005. Pp. 119-141.

Pérez Cepeda, A.I.: «La responsabilidad de los Administradores de sociedades: criterio de atribución». Editado por CEDECS. Barcelona, 1997.

20 Ver Morales Prats, F.: «La responsabilidad penal de las personas jurídicas. La Reforma Penal de 2010; análisis y comentarios». Editado por Aranzadi y dirigido por Gonzalo Quintero Olivares. Barcelona 2010, pp. 45-71 
GADEA SOLER, E. 2020. «Análisis de riesgos y evaluación de impacto relativa a la protección de datos: su aplicación a las sociedades cooperativas». Boletín de la Asociación Internacional de Derecho Cooperativo, n. 56 (abril), 47-72. https://doi.org/10.18543/baidc-56-2020pp47-72.

GADEA, E., SACRISTÁN, F. y VARGAS VASSEROT, C.: «Régimen jurídico de la Sociedad cooperativa del Siglo XXI. Realidad actual y propuestas de reforma». Editado por Dykinson, S.L. Madrid 2009.

GADEA, E.: «Derecho de las cooperativas. Análisis de la Ley 4/1993, de 24 de junio, de cooperativas del País Vasco». Editado por la Universidad de Deusto. Bilbao 1999.

GÓMEZ DE LA IGLESIA, R.: «El Fondo de Educación y Promoción Cooperativa». Editado por la Federación de Cooperativas de Trabajo Asociado de Euskadi. Vitoria-Gasteiz 1994.

GONDRA ELGEZABAL, G.: «Administratzaileen erantzukizuna Euskadiko Gizarte Ekonomiako enpresentan: Bereziki Kooperatiba Elkarteetan». Revista Vasca de Economía Social; n. ${ }^{\circ}$ 1. Editado por la Universidad del País Vasco. (UPV/EHU). Donostia-San Sebastián 2005.

MATA DIESTRO, H. 2018. «Fondos sociales obligatorios: la justificación de su irrepartibilidad en los orígenes del cooperativismo y del movimiento obrero organizado». Boletín de la Asociación Internacional de Derecho Cooperativo, n. 53 (diciembre), 289-307. https://doi.org/10.18543/baidc-532018pp289-307.

MORALES PRATS, F.: «La responsabilidad penal de las personas jurídicas», La Reforma Penal de 2010; Análisis y comentarios, editado por Aranzadi y dirigido por Gonzalo Quintero Olivares. Barcelona 2010.

MORILLAS JARILLO, M.J.: »La responsabilidad de los administradores de las sociedades cooperativas: mosaico legal e interpretación judicial». CIRIEC-España, Revista Jurídica de economía social y cooperativa, n. ${ }^{\circ}$ 28/2016. Madrid 2016.

NAGORE, I.: «Regulación en la legislación cooperativa vasca de la contribución para la educación y promoción cooperativa y otros fines de interés público y cuestiones que plantea». Boletín de la Asociación Internacional de Derecho Cooperativo, n. ${ }^{\circ}$ 57. Bilbao 2020, 253-278. https://doi.org/10.18543/ baidc-57-2020pp253-278.

PÉREZ CEPEDA, A.I.: "La responsabilidad de los Administradores de sociedades: criterio de atribución». Editado por CEDECS. Barcelona, 1997. 


\section{Derechos de autor}

El Boletín de la Asociación Internacional de Derecho Cooperativo es una revista de acceso abierto lo que significa que es de libre acceso en su integridad inmediatamente después de la publicación de cada número. Se permite su lectura, la búsqueda, descarga, distribución y reutilización legal en cualquier tipo de soporte sólo para fines no comerciales y según lo previsto por la ley; sin la previa autorización de la Editorial (Universidad de Deusto) o el autor, siempre que la obra original sea debidamente citada (número, año, páginas y DOI si procede) y cualquier cambio en el original esté claramente indicado.

\section{Copyright}

The International Association of Cooperative Law Journal is an Open Access journal which means that it is free for full and immediate access, reading, search, download, distribution, and lawful reuse in any medium only for non-commercial purposes, without prior permission from the Publisher or the author; provided the original work is properly cited and any changes to the original are clearly indicated. 